\title{
A GaN-Based Synchronous Buck Converter for High Power Laser Diode Drive Applications
}

\author{
A. Ugur, and M. Yilmaz
}

\begin{abstract}
Laser Diodes are the essential components for development of high power laser systems. To operate these devices, highly efficient and high power density, compact, current regulated switching converters are necessary. In this paper, Gallium Nitride (GaN) based synchronous buck converters are studied for the application of laser diode driver. For this purpose, two synchronous buck converters one with $\mathrm{Si}$-based the other one with GaN-based are designed, simulated, tested and compared. With the application of GaN-based semiconductors, 96.6\% efficiency and $9.1 \mathrm{~W} / \mathrm{cm}^{3}$ power density is achieved for $11 \mathrm{~A}, 28 \mathrm{~V}$ load at $700 \mathrm{kHz}$ operating frequency.
\end{abstract}

Index Terms-High power laser diode, Synchronous buck converter, GaN Transistor, power density, efficiency.

\section{INTRODUCTION}

$\mathrm{H}$ IGH POWER LASER SYSTEMS has an increasing demand in several areas such as material processing, drilling, manufacturing, defense applications and consumer electronics. For these systems high-power Continuous Wave (CW) fiber lasers are the ideal technology because of several reason including high efficiency, high reliability, compactness, low cost and simplicity. Due to their advantages, high power fiber lasers are not only replacing other laser systems but also non-laser systems in many applications [1]. On the other hand, fiber lasers are the coherent photon sources based on the excitation of gain medium (doped fiber) with diode pumps namely laser diodes [2]. Therefore; for high power single mode $\mathrm{CW}$ fiber laser pumping, high power and high brightness laser diodes are required.

Over the last decades, laser diodes with wavelength from 0.8 um to lum have improved significantly in terms of electrical-to-optical efficiency and compactness [3]. Today, laser diode modules available on the market are capable of $200 \mathrm{~W}$ optical power output with efficiency up to $65 \%$ in very compact packages. On the other hand, although $\$ / \mathrm{W}$ for laser diode modules decreased significantly lately, a module over 100W optical power still might cost more than 2,000\$.

A. UGUR, is with Department of Electrical Engineering, University of Istanbul Technical University, Istanbul, Turkey, (e-mail: ugurab@itu.edu.tr) (iD)

$\triangle$ M. YILMAZ, is with Department of Electrical Eng., University of Istanbul Technical University, Istanbul, Turkey, (e-mail: myilmaz@itu.edu.tr) (iD

Manuscript received October 16, 2017; accepted January 4, 2018. DOI: $10.17694 /$ bajece. 402018
Therefore using reliable drivers for these expensive devices is especially important. Electrically, laser diodes behave like LEDs with higher turn-on threshold voltage therefore driving low power laser diodes is similar to LED drivers. For low power laser diodes, a regulator operating amplifier which controls the current flowing through the laser diode via a sense resistor can be used. A simplified circuitry of a low power laser diode driver is shown in Fig. 1. High power laser diodes on the other hand, are similar to series LED strings applications where switching regulators are necessary to improve efficiency. Buck converters which are used in the industry up to $\mathrm{kW}$ power range are ideal for such applications due to the output filter inductor.

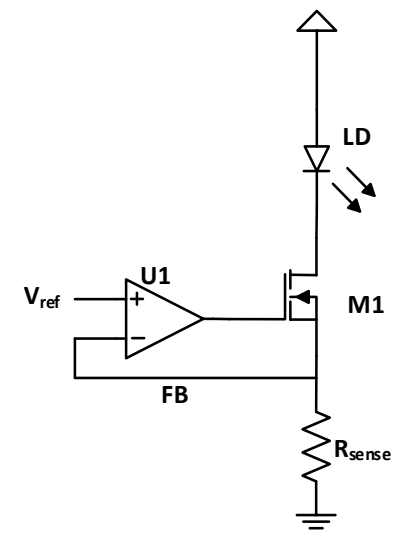

Fig. 1. Simplified circuit for low power laser diode driver

In recent years, switching devices using wide-bandgap (WBG) semiconductor materials such as Gallium Nitride (GaN) and Silicon Carbide (SiC) are improved significantly [4]-[6]. These devices offer very attractive characteristics such as high frequency switching and low on-state resistance which are crucial to achieve compact very efficient power converters. For this reason in this study, synchronous buck converters with $\mathrm{GaN}$ and Si based switching devices are designed and compared to understand the feasibility of GaN transistors for laser diode driving applications.

The structure of this paper is as follows: In Section II, the electrical characteristics of laser diodes are studied and the current/voltage requirements are determined. In Section III, the converter designs are presented. This part includes the basics of synchronous buck converter, circuit design, loss estimations of the GaN and Si based devices. In Section IV, the experimental results are shown; performances of the designed converters are compared and evaluated. 


\section{LASER DIODES}

As it was stated, high power laser diodes are essential components for high power laser systems. The current laser diode technology is based on combining multiple emitter semiconductor chips. The performance and rated power summary of several laser diode modules can be found in [7]. Although there are many different high power laser diode modules exist in the market, for simplicity in this study, a 976 nm $90 \mathrm{~W}$ laser diode module (Fig. 2) for which the test data given in Fig. 3 is taken as a reference.

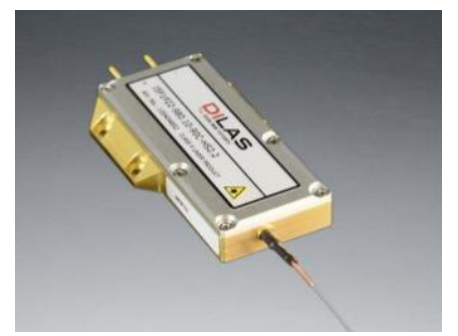

Fig. 2. 976nm, 90W fiber coupled laser diode module [8]

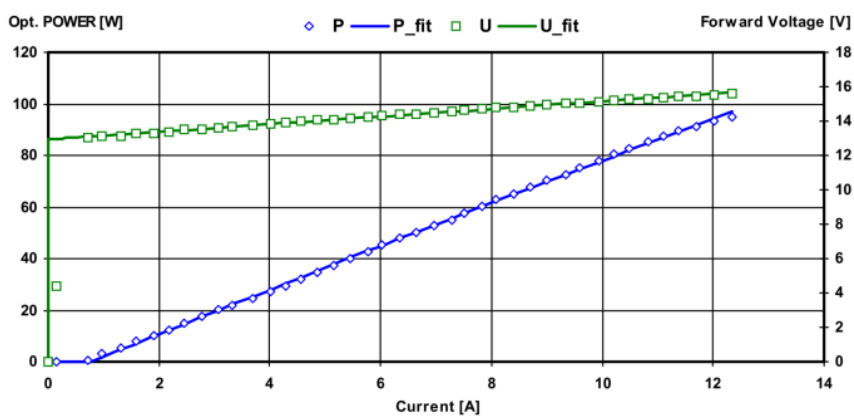

Fig. 3. Test data of a 976nm, 90W fiber coupled laser diode module [8].

The electrical characteristics of such module can be modelled as in Fig. 4, where $V_{\text {th }}(12.94 \mathrm{~V})$ is the threshold voltage and $R_{s}$ $(0.22 \Omega)$ is the on resistance of the device [8]. The rated voltage and current values are given as $15.5 \mathrm{~V}$ and $11.5 \mathrm{~A}$ respectively which corresponds to $50 \%$ electrical-to-optical efficiency.

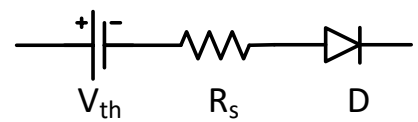

Fig. 4. Electrical model for a high power laser diode module.

Based on these considerations, for the application in this study the power ratings of the converters to be designed is determined as up to $11 \mathrm{~A} / 300 \mathrm{~W}$ output, which covers the electrical needs of many laser diode modules currently available on the market. Specifications of the load assumption are on Table 1.

TABLE I. SPECIFICATIONS OF THE LOAD ASSUMPTION

\begin{tabular}{|l|l|}
\hline Rated Current & $11 \mathrm{~A}$ \\
\hline Rated Voltage & $27 \mathrm{~V}$ \\
\hline Threshold Voltage of the load $\left(\mathrm{V}_{\mathrm{th}}\right)$ & $21.5 \mathrm{~V}$ \\
\hline On Resistance of the load $\left(\mathrm{R}_{\mathrm{on}}\right)$ & $0.5 \Omega$ \\
\hline
\end{tabular}

\section{CONVERTER DESIGN}

\section{A. Synchronous buck converter basics}

Synchronous buck converters are used to step down voltages from higher level to lower level. Basic schematic is given in Fig. 5. The operation principle is as follows: the $\mathrm{Q}_{1}$ MOSFET is connected to input voltage. When it is turned-on, the current flows from input to output, the current of the inductor increases and energy stored in the inductor. During this time $\mathrm{Q}_{2}$ MOSFET is off. When $\mathrm{Q}_{1}$ is turned-off and $\mathrm{Q}_{2}$ is turned-on, the current flows through $\mathrm{Q}_{2}$ in reverse direction, the current on the inductor decreases and some of the energy stored on the inductor is transferred to the load. The basic waveforms are given in Fig. 6.

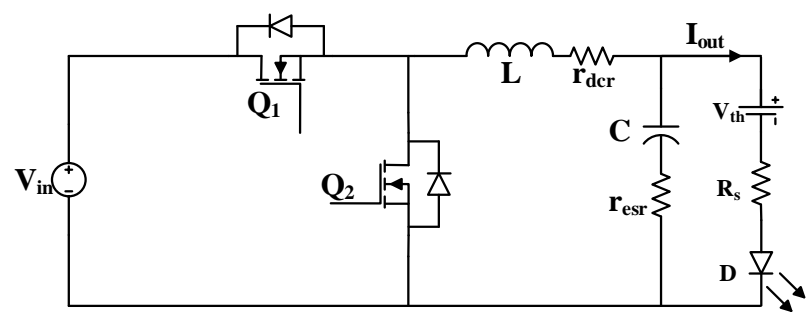

Fig. 5. Synchronous buck converter

The difference between the non-synchronous and synchronous buck converters is that the low side switch is a diode in non-synchronous one whereas it is transistor in the synchronous buck. Since in synchronous buck converter reverse current flow is allowed, efficiency is low compared to non-synchronous buck converter at light load. On the other hand at heavy load, synchronous buck converters have better efficiency due to low conduction losses in the low side switching device, and are preferred over traditional buck converter especially in the applications where the converter is expected to operate with heavy load.

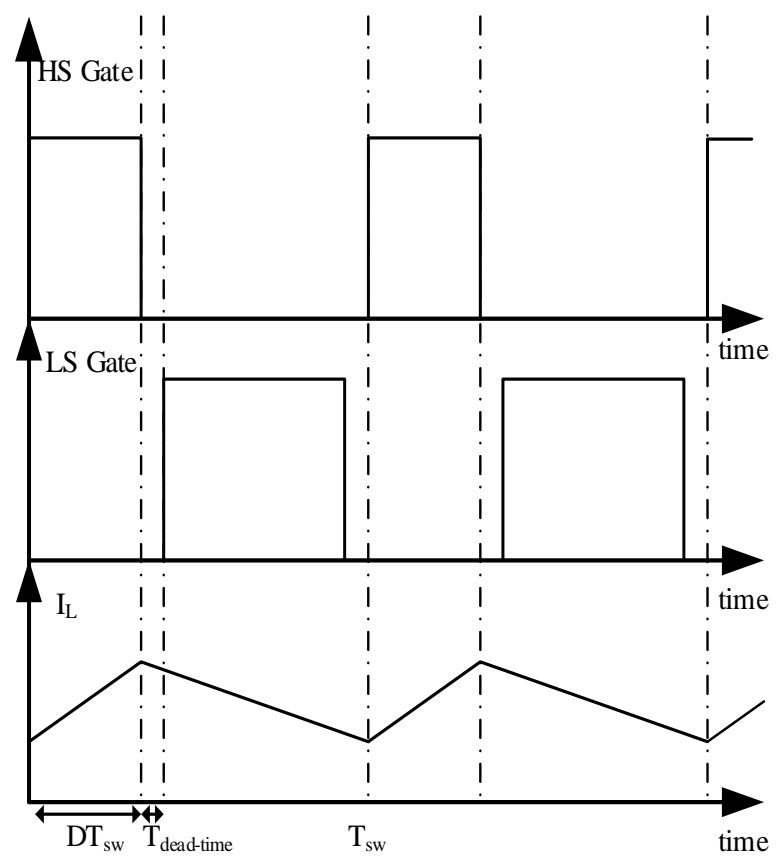

Fig. 6. Synchronous buck converter basic waveforms 


\section{B. Consideration of GaN and Si based switching devices}

Since there are many parameters which effect the performance of a converter, it is not an easy case to select the transistors. Main performance measures for selecting the semiconductors are the power loss and power dissipation capability. One simple way to compare the semiconductors and to determine the most suitable ones is to use Figure of Merit (FOM). For power converters, the loss is directly related with the on resistance $\left(\mathrm{R}_{\mathrm{DS}(\mathrm{on})}\right)$ and gate charge $\left(\mathrm{Q}_{\mathrm{g}}\right)$ of the transistors. Therefore, comparison of $\mathrm{Q}_{\mathrm{g}} \times \mathrm{R}_{\mathrm{DS}(\mathrm{on})} \mathrm{FOM}$ for transistors provide a good measure to estimate performance of the converter with different transistors. In Table 2, comparison of several parameters for the GaN transistor and Si-MOSFETs which are used in this study are given.

TABLE II. COMPARISON OF GaN AND SI BASED SWITCHING DEVICES IMPLEMENTED IN THIS STUDY

\begin{tabular}{|l|l|l|l|}
\hline & GS61008P & SiJ478DP (HS) & SiJ482DP (LS) \\
\hline $\mathrm{V}_{\mathrm{DS}}$ & $100 \mathrm{~V}$ & $80 \mathrm{~V}$ & $80 \mathrm{~V}$ \\
\hline $\mathrm{I}_{\mathrm{D}}$ & $90 \mathrm{~A}$ & $60 \mathrm{~A}$ & $60 \mathrm{~A}$ \\
\hline $\begin{array}{l}\mathrm{R}_{\mathrm{DS}(\text { on) }}\left(\mathrm{V}_{\mathrm{GS}}=6 \mathrm{~V},\right. \\
\left.\mathrm{T}_{\mathrm{J}}=25^{\circ} \mathrm{C}\right)\end{array}$ & $7 \mathrm{~m} \Omega$ & $7 \mathrm{~m} \Omega$ & $6 \mathrm{~m} \Omega$ \\
\hline $\begin{array}{l}\text { Normalized on- } \\
\text { state resistance }\left(\mathrm{T}_{\mathrm{J}}\right. \\
\left.=125^{\circ} \mathrm{C}\right)\end{array}$ & 2 & 1.6 & 1.6 \\
\hline $\begin{array}{l}\mathrm{Q}_{\mathrm{g}}\left(\mathrm{V}_{\mathrm{GS}}=6 \mathrm{~V}, \mathrm{~T}_{\mathrm{J}}=\right. \\
\left.25^{\circ} \mathrm{C}, \mathrm{V}_{\mathrm{DS}}=50 \mathrm{~V}\right)\end{array}$ & $12 \mathrm{nC}$ & $22 \mathrm{nC}$ & $24 \mathrm{nC}$ \\
\hline $\begin{array}{l}\text { Reverse recovery } \\
\text { charge }\left(\mathrm{Q}_{\mathrm{rr}}\right)\end{array}$ & - & $36 \mathrm{nC}$ & $44 \mathrm{nC}$ \\
\hline $\begin{array}{l}\text { Junction-to-case } \\
\text { thermal resistivity } \\
\left.\text { ( } \mathrm{R}_{\text {thJ }}\right)\end{array}$ & $0.55^{\circ} \mathrm{C} / \mathrm{W}$ & $1.5{ }^{\circ} \mathrm{C} / \mathrm{W}$ & $1.3{ }^{\circ} \mathrm{C} / \mathrm{W}$ \\
\hline $\begin{array}{l}\text { Reverse } \\
\text { conduction voltage } \\
\left(\mathrm{V}_{\mathrm{SD}}\right)\end{array}$ & $2 \mathrm{~V}$ & $0.76 \mathrm{~V}$ & $0.73 \mathrm{~V}$ \\
\hline
\end{tabular}

Although the rated voltage and current values are higher for the selected $\mathrm{GaN}$ transistor, it has better $\mathrm{Q}_{\mathrm{g}} \mathrm{R}_{\mathrm{DS}(\mathrm{on})} \mathrm{FOM}$ compared the $\mathrm{Si}$ MOSFETs. As for $\mathrm{R}_{\mathrm{DS}(\mathrm{on})}, \mathrm{Si}$ and $\mathrm{GaN}$ transistors have similar values at $25^{\circ} \mathrm{C}$ when the gate voltage is $6 \mathrm{~V}$. On the other hand, $\mathrm{R}_{\mathrm{DS}(\mathrm{on})}$ is highly related with the applied $\mathrm{V}_{\mathrm{GS}}$ voltage. For Si-MOSFETs the conduction losses can be decreased by applying higher turn-on gate voltages, although this leads some more gate drive and switching losses. Unlike Si-MOSFETs, higher gate voltages are not possible for $\mathrm{GaN}$ since the absolute maximum gate voltage is specified $7 \mathrm{~V}$ for these devices. One important point is that, the normalized onstate resistance of $\mathrm{GaN}$ transistor selected for this study is higher than the Si counterparts, so at high temperatures, the conduction losses are expected to be higher for $\mathrm{GaN}$ transistors.

On the other hand, the gate charge of the $\mathrm{GaN}$ transistor is significantly lower than the Si-MOSFETs, which leads lower switching losses, and enables operating at higher frequency.

E-mode GaN transistors do not need intrinsic body diode, therefore reverse recovery losses do not exist. However, in reverse direction $\mathrm{GaN}$ transistors have channel resistance which can be modelled as a body diode and this leads higher losses during the dead-time [9]. Therefore dead-time optimization is an important task for these devices. An analysis of the dead- time for GaN can be found in [10]. In this study two different dead-time is implemented to see the effect of the dead-time to GaN-based prototype.

\section{Loss Estimation}

In a synchronous buck converter the major losses are as follows:

- High side MOSFET conduction loss

- Low side MOSFET conduction loss

- High side MOSFET switching loss

- High side MOSFET gate charge loss

- High side MOSFET output capacitance loss

- Reverse recovery loss

- Dead-time loss

- Inductor loss

The losses can be estimated by using switching device datasheets [11], [12]. Conduction losses are result of the onstate resistances and can be calculated via Eq. (1) and Eq. (2) for high side and low side transistors.

$$
\begin{gathered}
P_{\text {cond_HS }}=R_{D S(o n)_{-} H S} x I_{\text {Drms_HS }}{ }^{2} \\
P_{\text {cond_LS }}=R_{D S(\text { on)_LS }} x I_{\text {Drms_LS }^{2}}{ }^{2}
\end{gathered}
$$

$\mathrm{I}_{\text {Drms }}$ is the drain to source RMS current flowing through the MOSFETs and can be approximated as $I_{\text {out }} D$ for $I_{\text {Drms_Hs }}$ and

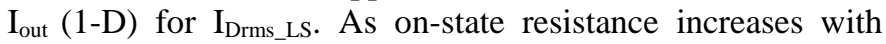
temperature, usually iterative calculations are applied. For this study, the maximum operating temperature on-state resistance values are used for a safe estimation.

The switching transitions of the MOSFET during the turn-on are given in Fig. 7.

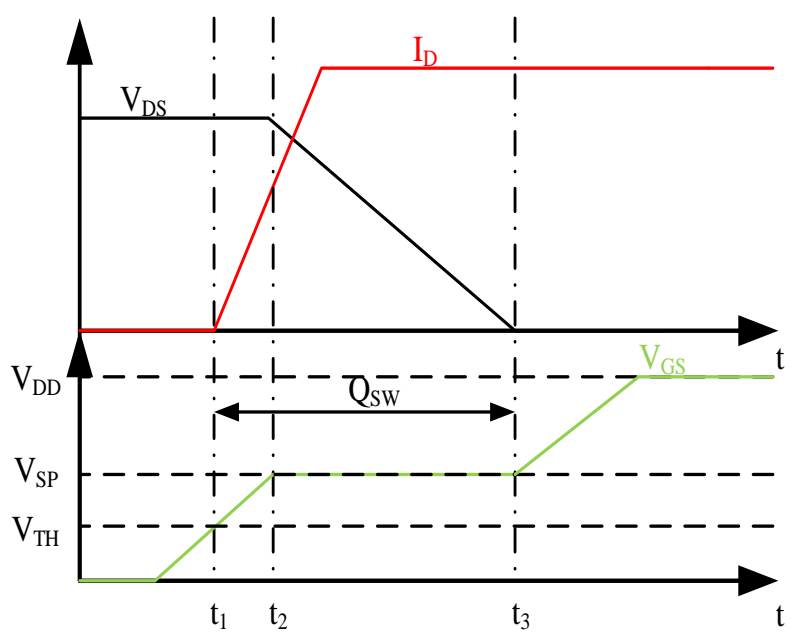

Fig. 7. Switching transitions of a typical MOSFET during turn-on High side MOSFET switching losses can be calculated by using switching gate charge $\left(\mathrm{Q}_{\mathrm{GSW}}\right)$ and gate currents $\left(\mathrm{I}_{\mathrm{G}}\right)$ as in Eq. (3).

$$
P_{S w_{H S}}=\frac{V_{I N} x I_{O U T}}{2} x f_{S w} x\left(\frac{Q_{G_{S W}}}{I_{G_{L H}}}+\frac{Q_{G_{S w}}}{I_{G_{H L}}}\right)
$$

$\mathrm{I}_{\mathrm{GHL}}$ and $\mathrm{I}_{\mathrm{GLH}}$ are the gate currents for high-to-low and low-tohigh transitions, respectively. Generally low-side MOSFET switching loss is neglected as it is low compared to other losses. 
Gate charge loss of the high side MOSFETs is expressed as in Eq. (4).

$$
P_{G_{H S}}=Q_{G} x V_{G a t e} x f_{s w}
$$

where $\mathrm{Q}_{\mathrm{G}}$ is total gate charge and $\mathrm{V}_{\mathrm{Gate}}$ is the driver's gate voltage. Loss due to the output capacitance $\left(\mathrm{C}_{\mathrm{OSS}}\right)$ of the highside switching device can be calculated with Eq. (5).

$$
P_{\text {COSS }}=C_{O S S} x V_{I N}^{2} x f_{s w} / 2
$$

The reverse recovery loss is calculated by using the reverse recovery charge $\left(Q_{R R}\right)$ via $\mathrm{Eq.} \mathrm{(6).}$

$$
P_{D_{R R}}=Q_{R R} x V_{I N} x f_{S w}
$$

The dead-time loss is calculated via Eq. (7).

$$
P_{D T}=T_{d} x V_{S D} x f_{S W} x I_{O U T}
$$

Here $T_{d}$ is dead-time, $V_{S D}$ is reverse voltage on the low-side MOSFET when both switches are off.

Finally, the inductor loss is a result of equivalent series resistance of the inductor $\left(\mathrm{R}_{\mathrm{ESR}(\mathrm{L})}\right)$ and described as in Eq. (8).

$$
P_{\text {Ind }}=R_{E S R(L)} x I_{O U T}^{2}
$$

Then total loss of the converter can be expressed as in Eq. (9).

$$
\begin{gathered}
P_{\text {TOTAL }}=P_{\text {cond_HS }}+P_{\text {cond_LS }}+P_{S w_{H S}}+P_{G_{H S}} \\
+P_{D_{R R}}+P_{D T}+P_{C O S S}+P_{\text {Ind }}
\end{gathered}
$$

\section{Specifications of the Converters}

The selection of the size of the inductor is straight forward and can be calculated for $30 \%$ peak-to-peak ripple current at maximum current via Eq. (10). The converters are designed for an operating frequency $500 \mathrm{kHz}$.

$$
L=\frac{V_{\text {OUT }} x\left(V_{I N}-V_{\text {OUT }}\right)}{0.3 x I_{\text {OUT }} x V_{I N} x f_{S W}}
$$

The output capacitor size has been selected for a $1 \%$ output current ripple $\left(\mathrm{I}_{\text {ripple }}\right)$. This ripple corresponds to $\mathrm{I}_{\text {ripple }} \mathrm{R}_{\mathrm{s}}$ voltage ripple $\left(\mathrm{V}_{\text {ripple }}\right)$ at the output. The maximum ESR of the capacitor is calculated with Eq. (11).

$$
R_{\text {cap_esr }}=\frac{V_{\text {ripple }}}{I_{\text {OUT }}}
$$

This is the maximum ESR value for ripple selection. The output capacitance can be calculated by using Eq. (12).

$$
C_{\text {OUT }_{\text {min }}}=\frac{\Delta I_{L}}{8 x I_{\text {OUT }} x f_{\text {sw }} x V_{\text {ripple }}}
$$

Based on these considerations, $6.8 \mathrm{uH}$ inductor and $2 \times 10 \mathrm{uF}$ ceramic capacitors at the output have been selected. Using ceramic capacitors has two advantages: first, they occupy less space on PCB which helps size reduction; second, low ESR reduces the output ripple. The details of the designed converters are given in Table 3 .
TABLE III. SPECIFICATIONS OF THE DESIGNED CONVERTERS

\begin{tabular}{|l|l|l|}
\hline & $\begin{array}{c}\text { Si-Si synchronous } \\
\text { buck converter }\end{array}$ & $\begin{array}{c}\text { GaN-GaN synchronous } \\
\text { buck converter }\end{array}$ \\
\hline HS transistor & SiJ478DP & GS61008P \\
\hline LS transistor & SiJ482DP & GS61008P \\
\hline Inductor & $6.8 \mathrm{uH}$ & $6.8 \mathrm{uH}$ \\
\hline Output Capacitor & $2 \times 10 \mathrm{uF}$ & $2 \times 10 \mathrm{uF}$ \\
\hline Gate Driver & $\mathrm{UCC} 27211$ & $\mathrm{LM} 5113$ \\
\hline Gate Voltage & $12 \mathrm{~V}$ & $5 \mathrm{~V}$ \\
\hline Gate Resistors & 4.7 & $\mathrm{R}_{\text {on }}=4.7, \mathrm{R}_{\text {off }}=1$ \\
\hline
\end{tabular}

In Fig. 8, the LT-Spice simulation model has been given. In the simulation model, the capacitor and inductor ESR values have been included with small parasitic inductances on the high di/dt loop. As it can be seen from Fig. 9, the current ripple on the laser diode is below $1 \%$ with and the inductor current ripple is around $30 \%$.

\section{E. Efficiency comparison of GaN and Si based synchronous} buck converters

Efficiency comparison has been done at $60 \%$ duty cycle operation and for 11A output current.

For Si-Si based synchronous buck converter $97.7 \%$ and $97.3 \%$ efficiency has been calculated for $400 \mathrm{kHz}$ and $500 \mathrm{kHz}$ operation respectively and the distribution of the calculated loss has been shown in Fig. 10. Note that, the dead-time has been taken as $20 \mathrm{~ns}$ for this converter.

For GaN-GaN based synchronous buck converter estimated efficiency for $10 \mathrm{~ns}$ and $20 \mathrm{~ns}$ dead-time has been given Table 4. For this converter, the distributions of the losses are given in Fig. 11 and Fig. 12.

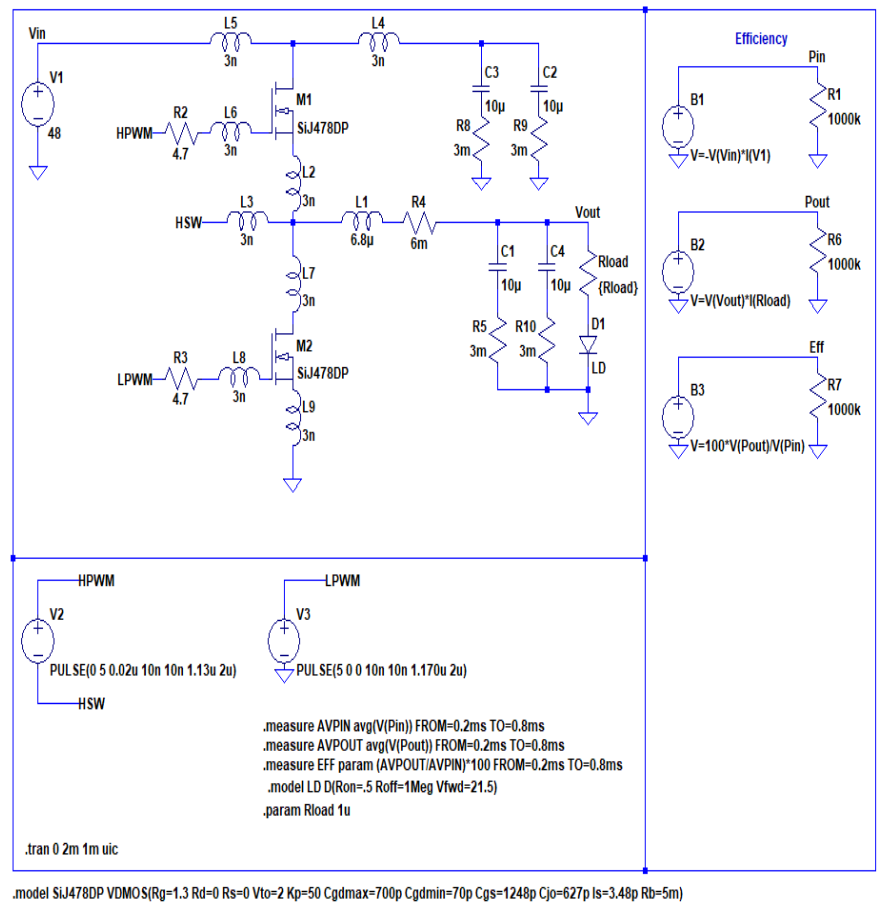

Fig. 8. Simulation model of the synchronous buck converter 


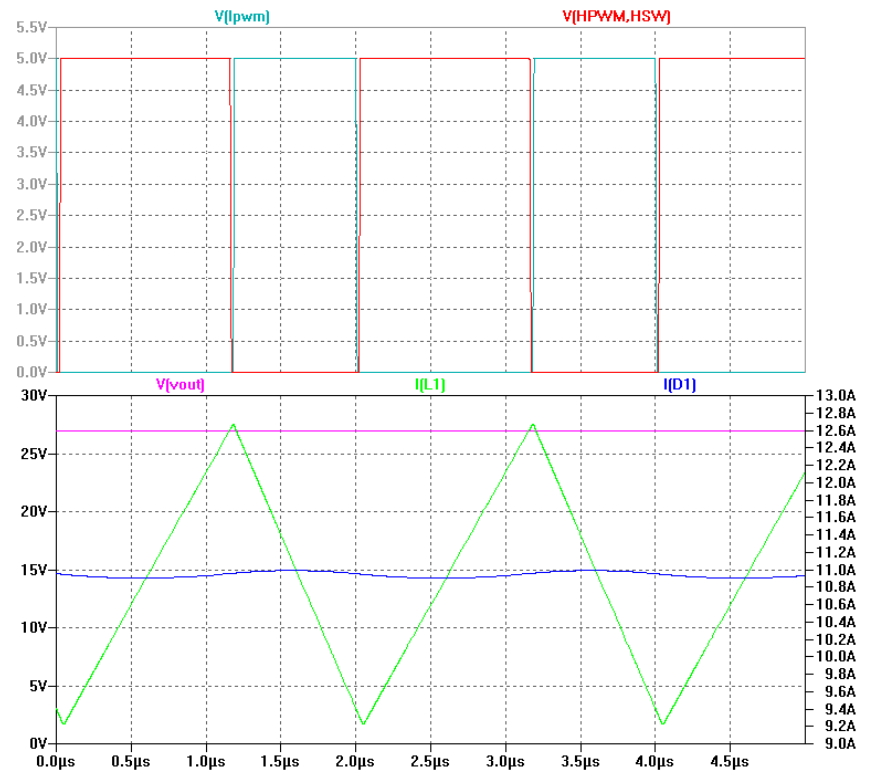

Fig. 9. Simulation results of the synchronous buck converter

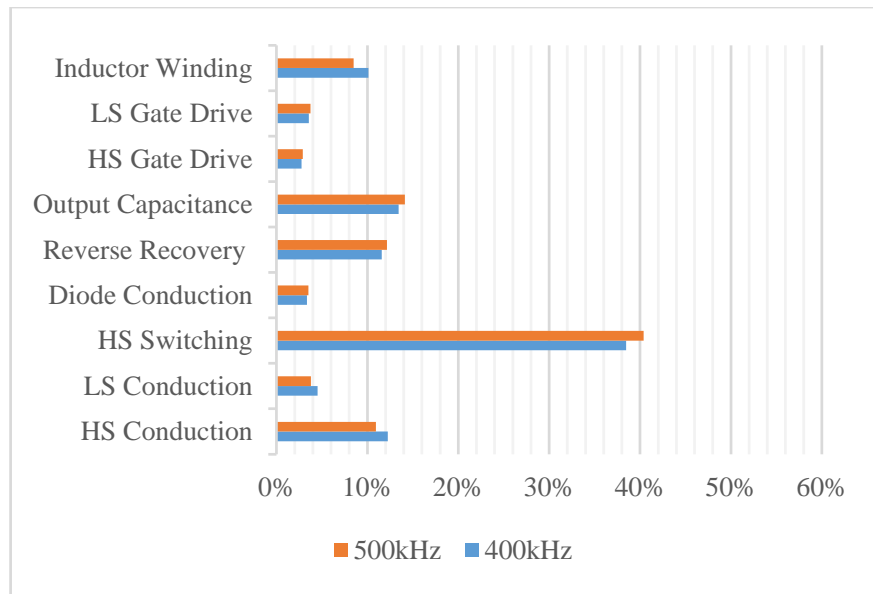

Fig. 10 Si-Si synchronous buck converter estimated loss distribution.

\section{TABLE IV. CALCULATED EFFICIENCY FOR GaN-GaN BASED} SYNCHRONOUS BUCK CONVERTER

\begin{tabular}{|c|c|c|}
\hline $\begin{array}{c}\text { Frequency } \\
{[\mathrm{kHz}]}\end{array}$ & $\begin{array}{c}\text { Dead-time } \\
{[\mathrm{ns}]}\end{array}$ & $\begin{array}{c}\text { Calculated } \\
\text { Efficiency }\end{array}$ \\
\hline 400 & 20 & $98.3 \%$ \\
\hline 500 & 20 & $97.9 \%$ \\
\hline 600 & 20 & $97.6 \%$ \\
\hline 700 & 20 & $97.4 \%$ \\
\hline 400 & 10 & $98.2 \%$ \\
\hline 500 & 10 & $97.8 \%$ \\
\hline 600 & 10 & $97.5 \%$ \\
\hline 700 & 10 & $97.2 \%$ \\
\hline
\end{tabular}

According to the calculations slightly better efficiency is expected in GaN-based prototype due to reduced switching charge of $\mathrm{GaN}$ transistors. Please note that, as expected diode conduction loss is more in GaN-based synchronous buck converter, although its effect to the total loss has been reduced with 10 ns dead-time as in Fig. 12.

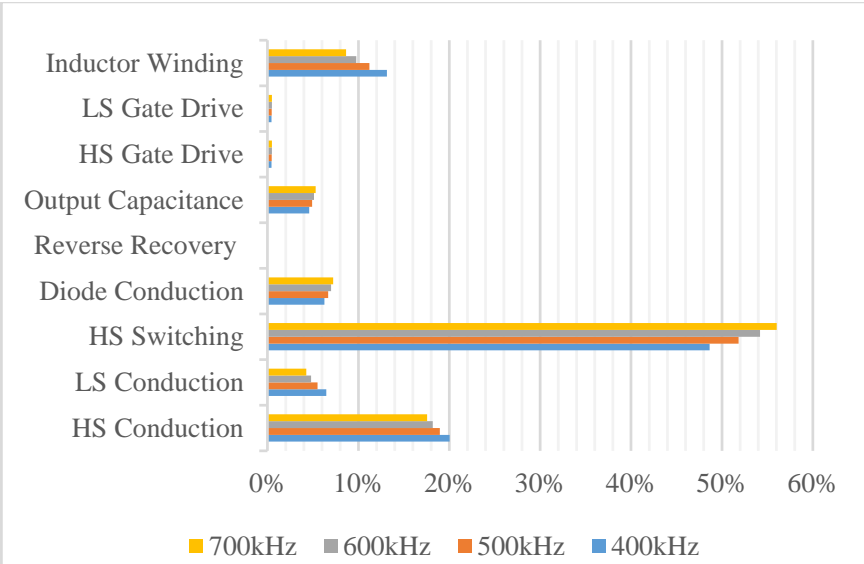

Fig. 11. GaN-GaN synchronous buck converter estimated loss distribution with $20 \mathrm{~ns}$ dead-time

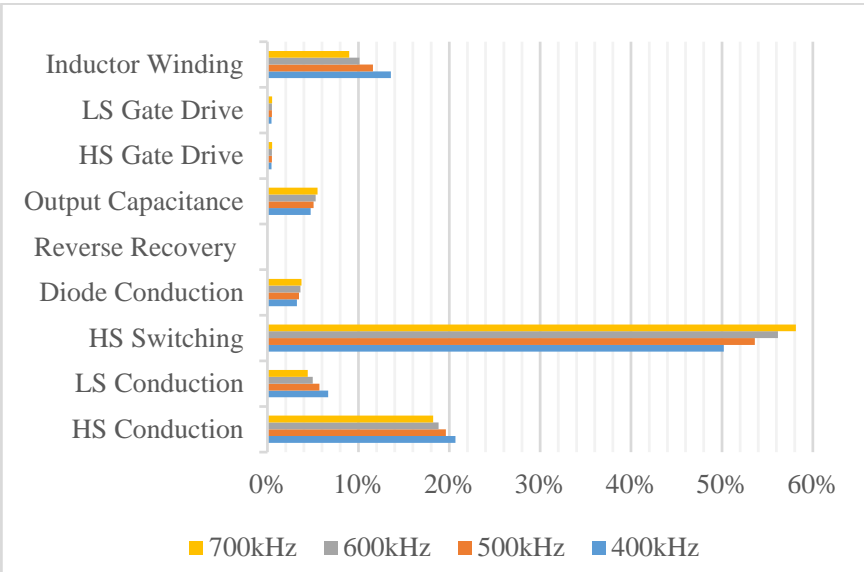

Fig. 12. GaN-GaN synchronous buck converter estimated loss distribution with 10 ns dead-time.

\section{EXPERIMENTAL RESULTS}

The converters are designed on very compact $30 \times 100 \times 11 \mathrm{~mm}$ PCBs (Fig. 13) based on the specifications given in Table 3. During the tests forced air cooling is applied with fans. A photo of the test bench can be seen on Fig. 14. An electronic load is used to output of the converters.

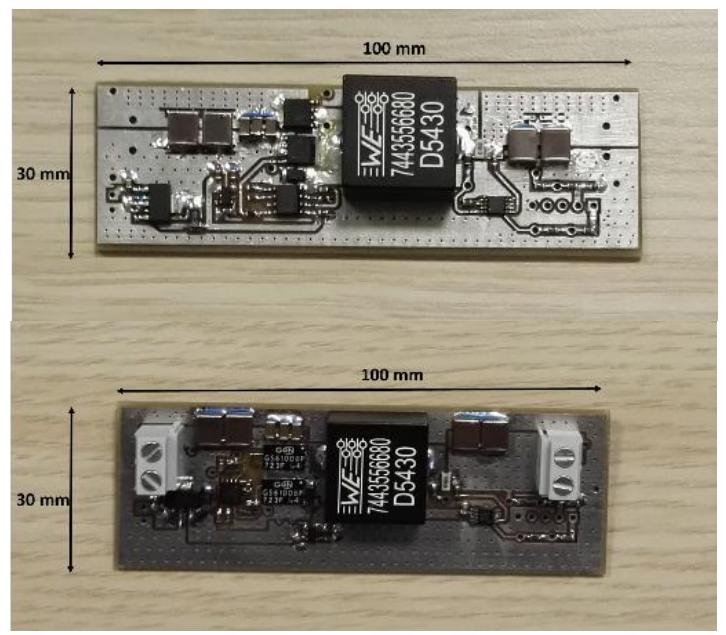

Fig. 13. Si-Si (Top) and GaN-GaN synchronous buck converter prototypes 
The experimental results with $11 \mathrm{~A} 60 \%$ duty cycle are shown in Table 5 for $\mathrm{GaN}-\mathrm{GaN}$ prototype and in Table 6 for $\mathrm{Si}-\mathrm{Si}$ prototype. At $400 \mathrm{kHz}$ and $500 \mathrm{kHz}$ very similar efficiency values have been measured which shows that at these frequencies Si-MOSFETs can still provide very good results in terms of efficiency. However, with the application of $\mathrm{GaN}$ switching devices, it is possible to implement higher operating frequencies. As it can be seen in Table 5 at $700 \mathrm{kHz}$ with $10 \mathrm{~ns}$ $96.6 \%$ efficiency has been measured which is almost the same as in Si-based converter at $500 \mathrm{kHz}$.

On the other hand, as it can be seen in Fig. 15 and Fig. 16, the classical power loss estimation that is applied in this study provide limited results which suggests that the circuit parasitics are very effective although the circuit layout is designed as proposed in [13] and therefore should be taken into account for the cooling design.

Another observation is that for Gallium Nitride based prototype, the efficiency difference between $10 \mathrm{~ns}$ and $20 \mathrm{~ns}$ dead-time is up to $0.4 \%$, which shows that dead-time optimization is necessary for these converters. In Fig. 17 and Fig. 18, the $\mathrm{V}_{\mathrm{DS}}$ voltages of the high-side and low-side transistors are shown for different dead-time values. One important point is that although too long dead-time increases the losses, having too short can cause power input to ground short circuit which leads shoot through effect or can prevent the zero voltage turn-on of the low side MOSFET which results in reduced efficiency [10]. In this study, optimization of the deadtime is not considered however $10 \mathrm{~ns}$ dead-time provided good results.

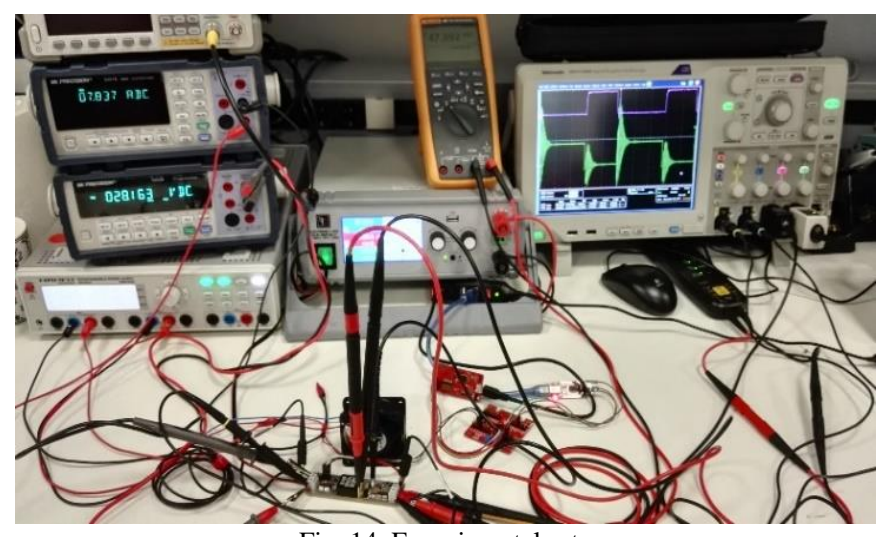

Fig. 14. Experimental setup

TABLE V. EXPERIMENTAL RESULTS OF THE GaN-GaN PROTOTYPE

\begin{tabular}{|c|c|c|}
\hline $\begin{array}{c}\text { Frequency } \\
{[\mathrm{kHz}]}\end{array}$ & $\begin{array}{c}\text { Dead-time } \\
{[\mathrm{ns}]}\end{array}$ & $\begin{array}{c}\text { Calculated } \\
\text { Efficiency }\end{array}$ \\
\hline 400 & 20 & $97.0 \%$ \\
\hline 500 & 20 & $96.8 \%$ \\
\hline 600 & 20 & $96.6 \%$ \\
\hline 700 & 20 & $96.2 \%$ \\
\hline 400 & 10 & $97.4 \%$ \\
\hline 500 & 10 & $97.2 \%$ \\
\hline 600 & 10 & $97.0 \%$ \\
\hline 700 & 10 & $96.6 \%$ \\
\hline
\end{tabular}

TABLE VI. EXPERIMENTAL RESULTS OF THE SI-SI PROTOTYPE

\begin{tabular}{|c|c|c|}
\hline Frequency $[\mathrm{kHz}]$ & Dead-time [ns] & Measured Efficiency \\
\hline 400 & 20 & $96.9 \%$ \\
\hline 500 & 20 & $96.7 \%$ \\
\hline
\end{tabular}

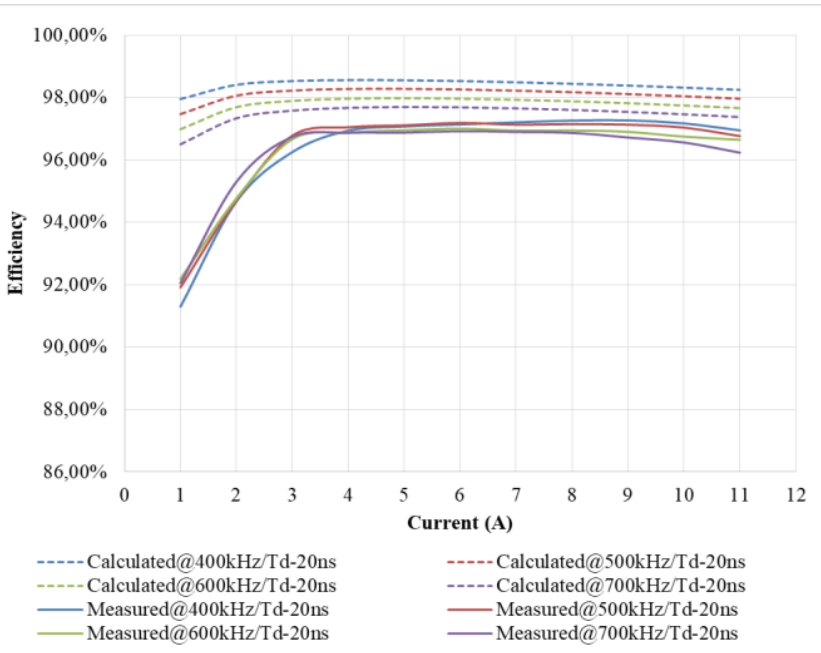

Fig. 15. Comparison of measured and calculated efficiencies for GaN-based synchronous buck converter with $20 \mathrm{~ns}$ dead-time

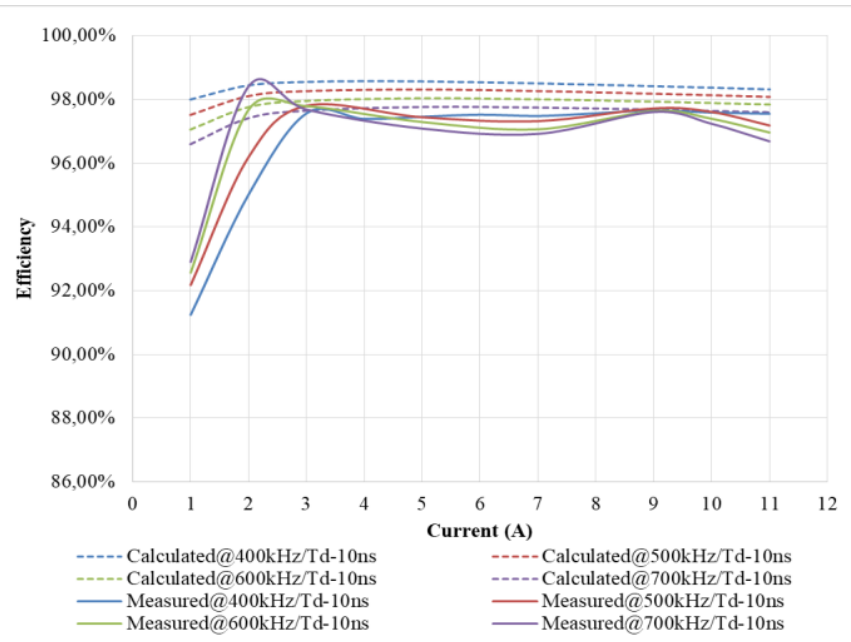

Fig. 16. Comparison of measured and calculated efficiencies for GaN-based synchronous buck converter with 10ns dead-time.

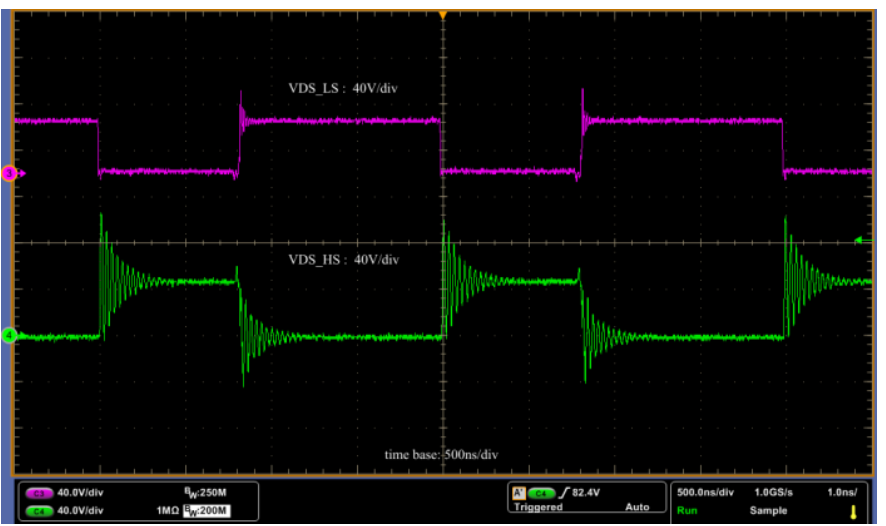

Fig. 17. GaN-based prototype high-side (green) and low-side (purple) $V_{D S}$ voltage waveforms and overshoot at $500 \mathrm{kHz} / 20 \mathrm{~ns}$ dead-time with $8 \mathrm{~A}$ load. 


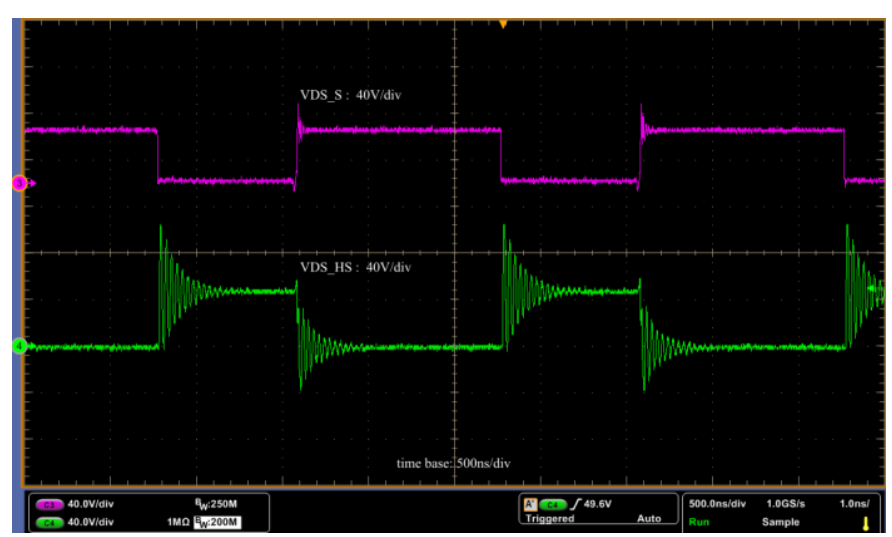

Fig. 18. GaN-based prototype high-side (green) and low-side (purple) $\mathrm{V}_{\mathrm{DS}}$ voltage waveforms and overshoot at $500 \mathrm{kHz} / 10 \mathrm{~ns}$ dead-time with $8 \mathrm{~A}$ load.

\section{CONCLUSION}

In this study, compact, high efficient and power density synchronous buck converters are studied for high power laser diode drive applications. For this purpose, two synchronous buck converters one with Si-based the other one with GaNbased are designed, simulated, tested and compared. With the use of GaN switching devices, $96.6 \%$ efficiency at $700 \mathrm{kHz}$ is measured and without cooling and control circuitry $9.1 \mathrm{~W} / \mathrm{cm}^{3}$ power density is achieved for an $11 \mathrm{~A} / 300 \mathrm{~W}$ prototype which can be used for most of the high power laser diodes on the market. On the other hand, it is seen that optimization of the dead-time is necessary for $\mathrm{GaN}$ based synchronous buck converters to reduce the losses. The results shows that, GaN transistors are very promising semiconductor devices and can promote efficiency of the synchronous buck converters for high power laser diode drive applications.

\section{REFERENCES}

[1] D.A.V. Kliner, "nLIGHT alta: A versatile next-generation fiber laser platform for kW materials processing", in Proc. of the 84th Int. Conf. on Laser Mater. Process., Jan. 2016. pp. 1-7.

[2] J. Wallace, "Photonics Products: High-power Fiber Lasers: Kilowatt-level fiber lasers mature", Laserfocusworld.com, 2018. [Online]. Available: http://www.laserfocusworld.com. [Accessed: 24- Jan- 2018].

[3] L. Bao; J. Bai; K. Price; M. Devito; M. Grimshaw; W. Dong; X. Guan; S. Zhang; H. Zhou; K. Bruce; D. Dawson; M. Kanskar; R. Martinsen; J. Haden (2013). "Reliability of high power/brightness diode lasers emitting from $790 \mathrm{~nm}$ to $980 \mathrm{~nm}$." in Proc. of SPIE, Vol. 8605, pp. 86050N-1.

[4] J. Millan, P. Godignon, X. Perpina, A. Perez-Tomas, J. Rebollo, "A Survey of Wide Bandgap Power Semiconductor Devices," IEEE Trans. Power Electron., vol. 29, no.5, pp. 2155-2163, May 2014.

[5] M. Ishida, T. Ueda, T. Tanaka and D. Ueda, "GaN on Si Technologies for Power Switching Devices," IEEE Trans. on Electron Devices, vol. 60, no.10, pp.3053-3059, Oct 2013.

[6] X. Huang, Z. Liu, Q. Li and F. C. Lee, "Evaluation and Application of $600 \mathrm{~V}$ GaN HEMT in Cascode Structure," IEEE Trans. Power Electron., vol. 29 no. 5, pp. 2453-2461, May 2014.

[7] M. Kanskar, L. Bao, J. Bai, Z. Chen, D. Dahlen, M. DeVito, W. Dong, M. Grimshaw, J. Haden, X. Guan, M. Hemenway, K. Kennedy, R. Martinsen, J. Tibbals, W. Urbanek, S. Zhang (2014, March). "High reliability of high power and high brightness diode lasers", in Proc. of SPIE, March 2014, Vol. 8965, pp. 896508.

[8] DILAS, "976nm, 90W, conduction-cooled, fiber-coupled diode laser module", www.dilas.com, 2018 [Online]. Available: http://dilas.com/assets/media/products/DILAS_SE_Module-976nm90W_HS2-PM10_TD.pdf [Accessed:24-Jan-2018].

[9] GaN Systems, "Bottom-side cooled 100V E-mode GaN transistor," GS61008P datasheet, Rev. 180111.
[10] D. Han and B. Sarlioglu, "Deadtime Effect on GaN-Based Synchronous Boost Converter and Analytical Model for Optimal Deadtime Selection," IEEE Trans. Power Electron., vol. 31, no. 1, pp. 601-612, Jan. 2016.

[11] Fairchild, Appl. Note AN-6005.

[12] Microchip, Appl. Note AN-1471.

[13] D. Reusch and J. Styrdom, "Understanding the Effect of PCB Layout on Circuit Performance in a High-Frequency Gallium-Nitride-Based Point of Load Converter," IEEE Trans. Power Electron., vol.29, no.4, pp.20082015, April 2014.

\section{BIOGRAPHIES}

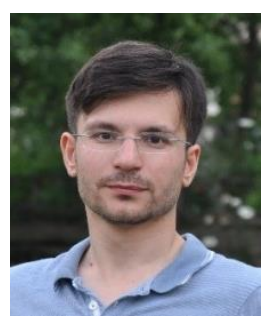

ABDULKERIM UGUR, received the B.Sc. degree in Electrical and Electronics Engineering from Middle East Technical University, Ankara, Turkey, in 2009 and M.Sc. degree in Electrical Engineering from the Istanbul Technical University, Istanbul, Turkey in 2012.

Currently he is a Ph.D. student at Istanbul Technical University. His research interests include power electronics and hardware design.

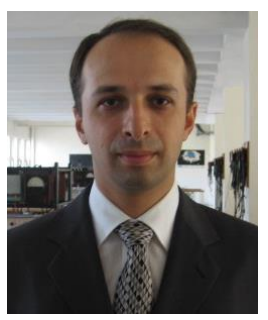

MURAT YILMAZ received the B.Sc. degree from Electrical Engineering Department, Istanbul Technical University (ITU), Istanbul, Turkey, in 1995 and the M.Sc. and Ph.D. degrees from the same university, 1995 and 2005, respectively.

$\mathrm{He}$ is currently an Assistant Professor at the Istanbul Technical University. His research interests power electronics and electrical machine design, control, optimization and reliability modeling in motor drives and electric drive vehicles including electric, hybrid and plug-in electric vehicles. 